\title{
Randomised clinical trial of two treatment regimens of natural surfactant preparations in neonatal respiratory distress syndrome
}

\author{
Christian P Speer, Olaf Gefeller, Peter Groneck, Edgar Laufkötter, Claudia Roll, \\ Ludwig Hanssler, Karsten Harms, Egbert Herting, Herbert Boenisch, Jürgen Windeler, \\ Bengt Robertson
}

Department of
Paediatrics, University
of Gottingen
C P Speer
K Harms
E Herting
Department of
Medical Statistics
O Gefeller
Department of
Paediatrics,
Städtisches
Krankenhaus, Koln
P Groneck

Department of Paediatrics, University of Bochum

E Laufkötter

Department of Paediatrics, University of Essen

C Roll

L Hanssler

Stădtisches

Krankenhaus

Braunschweig,

H Boenisch

Department of Medical Informatics and Biomathematics, University of Bochum $\mathrm{J}$ Windeler

Karolinska Institute, Research Unit for Experimental Perinatal Pathology, Karolinska Hospital, Stockholm, Sweden B Robertson

Correspondence to: Dr Christian P Speer, Department of Neonatology, University of Tübingen, Rümelinstraße 23, 72070 Tübingen, Germany.

Accepted 17 August 1994

\begin{abstract}
Aims-To compare treatment regimens of two widely used natural surfactant preparations Curosurf and Survanta in respiratory distress syndrome (RDS).

Methods-The effects of the two treatment regimens on gas exchange, ventilatory requirements, and 28 day outcome in infants with RDS were compared. Seventy five preterm infants (birth weight 700-1500 g) with RDS requiring artificial ventilation with an $\mathrm{FIO}_{2}$ of $\geqslant 0.4$, were randomly selected at 1-24 hours of age. One group received an initial dose of Curosurf (200 mg/kg); the other group Survanta (100 $\mathrm{mg} / \mathrm{kg}$ ). Patients who remained dependent on artificial ventilation with an $\mathrm{FIO}_{2}$ of $\geqslant 0.3$ received up to two additional doses of Curosurf (each of $100 \mathrm{mg} / \mathrm{kg}$ ) after 12 and 24 hours or up to three additional doses of Survanta (each of $100 \mathrm{mg} / \mathrm{kg}$ ) between six and 48 hours after the initial dose.

Results-There was a rapid improvement in oxygenation and ventilatory requirements were reduced in both groups. However, infants treated with Curosurf had a higher arterial:alveolar oxygen tension ratio and required a lower peak inspiratory pressure and mean airway pressure at several time points within 24 hours of randomisation $(p<0.05-0.001)$. The incidences of pneumothorax in the Curosurf and Survanta groups were $6 \%$ and $12.5 \%$, respectively; the corresponding figures for grades 3-4 intracerebral haemorrhage were $3 \%$ and $12 \cdot 5 \%$, respectively. Mortality was $3 \%$ in the Curosurf group and $12 \cdot 5 \%$ in the Survanta group. However, these differences did not reach significance.

Conclusion-The Curosurf treatment regimen resulted in a more rapid improvement in oxygenation than Survanta and reduced ventilatory requirements up to 24 hours after start of treatment. This was associated with a trend towards reduced incidence of serious pulmonary and nonpulmonary complications.

(Arch Dis Child 1995; 72: F8-F13)
\end{abstract}

Keywords: surfactant treatment, respiratory distress syndrome, Curosurf, Survanta.

Surfactant treatment with natural or synthetic preparations reduces the incidence of neonatal mortality and pneumothorax in babies with respiratory distress syndrome (RDS). ${ }^{1}$ Natural surfactants seem to improve oxygenation and lung function more rapidly than synthetic surfactants, ${ }^{2}$ but there have been no studies comparing the effects of two natural surfactants.

We designed a pilot trial to compare the acute effects of the bovine preparation Survanta (Beractant, Ross Laboratories, Columbus, Ohio, USA) and the porcine surfactant Curosurf (Chiesi Farmaceutici, Parma, Italy). The two surfactant preparations have been carefully evaluated in clinical trials ${ }^{3-6} 7-9$; they are licensed in Europe and have several features in common but differ in some potentially important biophysical characteristics. ${ }^{10}$

In preparation for a trial comparing therapeutic regimens involving these two natural surfactants, the present study was performed to test case record forms, compliance with randomisation guidelines in the collaborating centres, feasibility of monitoring procedures, adherence of centres to general good clinical principles, and for sample size calculations of a large definitive trial.

\section{Methods}

Curosurf is a natural surfactant, prepared from pig lungs. It contains almost exclusively polar lipids - in particular phosphatidylcholine (about $60 \%$ of the total phospholipids) and $1 \%$ of the specific hydrophobic low molecular weight apoproteins SP-B and SP-C. Further details of the composition and the physical properties have been described before. ${ }^{11}$ Survanta is a bovine lung extract containing phospholipids, neutral lipids, fatty acids, and surfactant associated apoproteins SP-B and SP-C. Dipalmitoylphosphatidylcholine, palmitic acid, and tripalmitin are added to standardise the composition, and to mimic the surfactant properties of natural lung surfactant. ${ }^{12}$

The present pilot study was designed to determine possible differences between the two surfactant treatment regimens. It was planned to recruit at least 35 infants for each treatment group. No short term endpoints relating to oxygenation or ventilator settings were defined. Five German neonatal intensive care units collaborated in this trial which started 1 December 1991 and ended 15 July 1992. The number of patients randomised by each unit varied because of differences in the 
Table 1 Number of patients randomised in each contributing unit

\begin{tabular}{llcc}
\hline \multirow{2}{*}{$\begin{array}{l}\text { Contributing } \\
\text { units }\end{array}$} & \multicolumn{2}{l}{ No of patients } & \\
\cline { 2 - 3 } & Curosurf & Survanta & Total \\
\hline Bochum & 2 & 5 & 7 \\
Braunschweig & 1 & 3 & 4 \\
Essen & $9^{\star}$ & 9 & 18 \\
Göttingen & 9 & 9 & 18 \\
Cologne & $14^{\star}$ & 14 & 28 \\
\hline
\end{tabular}

*One patient treated with Curosurf was excluded (violation of entry criteria).

size of the population from which they were recruited and because of differences in admission policies (table 1).

Criteria for entry were:

(i) birth weight 700-1500 g;

(ii) clinical and radiological findings typical of RDS;

(iii) age at randomisation of 1-24 hours;

(iv) requirement of artificial ventilation with a fraction of inspired oxygen $\left(\mathrm{FIO}_{2}\right)$ of $\geqslant 0 \cdot 4$;

(v) no complicating diseases; and

(vi) parental consent.

Complicating diseases leading to exclusion of infants were: (i) prolonged rupture of membranes (>3 weeks); (ii) intracranial haemorrhage (ICH) grade III-IV before randomisation; and (iii) severe birth asphyxia (Apgar score of $\leqslant 3$ at five minutes, umbilical arterial cord blood $\mathrm{pH}$ of $<7 \cdot 1$ ), or major congenital anomalies. Anaemia, hypotension, hypoglycaemia, acidosis, and pneumothorax and neonatal infection (with group B streptococci, for example) were treated by appropriate measures before surfactant replacement. Infants were excluded if they had persistent physiological instability such as hypotension, hypoglycaemia, and pneumothorax.

At randomisation, all infants were mechanically ventilated with an $\mathrm{FIO}_{2}$ of $\geqslant 0.4$ (entry criterion), a frequency of $40-80$ breaths/minute, a peak inspiratory pressure (PIP) of $<30 \mathrm{~cm}$ $\mathrm{H}_{2} \mathrm{O}$, a positive end expiratory pressure (PEEP) of $2-5 \mathrm{~cm} \mathrm{H}_{2} \mathrm{O}$, and an inspiration to expiration ratio of $1: 1$ to $1: 2$.

On a random basis, infants with RDS who met eligibility criteria were allocated to treatment with Curosurf or Survanta by means of sealed opaque envelopes. Stratified randomisation within each centre was applied with regard to birth weight (700-999 $\mathrm{g}$ and 1000-1500 g). After randomisation of a patient each contributing centre contacted the Biometric Centre at the University of Göttingen to provide centre number, patient's number, date of birth and treatment group. This informed the Biometric Centre of the inclusion of a new patient into the study, ensuring an objective verification of the randomisation sequence. Because the recommended doses, volumes, dose interval and dose procedures differed between both surfactant preparations, blinding of surfactant administration was not feasible.

All infants randomised to Curosurf treatment received $200 \mathrm{mg}$ of Curosurf $/ \mathrm{kg}$ bodyweight $(2.5 \mathrm{ml} / \mathrm{kg})$, divided in two portions instilled into each main bronchus. ${ }^{3}$ Retreatment with $100 \mathrm{mg} / \mathrm{kg}$ per dose was performed at 12 hours and 24 hours after the first treatment if the babies required an $\mathrm{FIO}_{2}$ of $\geqslant 0.3$ to keep $\mathrm{PaO}_{2}$ to $\geqslant 50 \mathrm{~mm} \mathrm{Hg}(\geqslant 6.7 \mathrm{kPa})$ on mechanical ventilation. Details of the instillation manoeuvre have been described before. ${ }^{4}$ The maximal cumulative dose was $400 \mathrm{mg} / \mathrm{kg}$.

Survanta was administered intratracheally at a dose of $100 \mathrm{mg} / \mathrm{kg}(4.0 \mathrm{ml} / \mathrm{kg})$ divided into four equal amounts, instilled into the four quadrants of the lung, as recommended by the manufacturer. Retreatment with Survanta was performed as early as 6 hours after the initial dose, provided the baby required an $\mathrm{FIO}_{2}$ of $\geqslant 0.3$ and was still on the ventilator. Six hours after the first dose until 48 hours of age, the patients could receive up to three additional treatments, no more than every six hours if they remained intubated and required an $\mathrm{FiO}_{2}$ of $\geqslant 0.3$ to maintain $\mathrm{PaO}_{2}$ of $\geqslant 50 \mathrm{~mm} \mathrm{Hg}$ $(\geqslant 6.7 \mathrm{kPa})$. Each of these doses was $100 \mathrm{mg} / \mathrm{kg}$ which means the maximum cumulative dose of Survanta was the same as for Curosurf $-400 \mathrm{mg} / \mathrm{kg}$. The retreatment doses (if required) were administered in two doses into each lung quadrant. Details of the instillation procedure have been reported. ${ }^{911}$

No suctioning of the airways was performed during the first six hours after instillation of Curosurf or Survanta. After surfactant administration the baby was reconnected to the ventilator, and $\mathrm{FIO}_{2}$ and ventilator settings were immediately adjusted according to clinical response to maintain adequate blood gases $\left(\mathrm{PaO}_{2}\right.$ of $\left.50-70 \mathrm{~mm} \mathrm{Hg}\right) ;\left(\mathrm{PaCO}_{2}\right.$ 40-50 $\mathrm{mm} \mathrm{Hg}, \mathrm{pH} \geqslant 7 \cdot 3$ ) with the lowest possible level of $\mathrm{FIO}_{2}$ and PIP. To obtain this goal, $\mathrm{FIO}_{2}$ was lowered first; subsequent adjustments included reduction of insufflation pressure and inspiration:expiration ratio. A PEEP of $2-5 \mathrm{~cm} \mathrm{H}_{2} \mathrm{O}$ was maintained during the first hours after surfactant instillation.

Arterial or transcutaneous blood gas values were determined at regular intervals (five, 30, 60 minutes; three, six, 12, 24 hours, and two, three, four, seven, and 10 days after surfactant replacement). The Curosurf and Survanta groups were compared with respect to the following measurements: $\mathrm{FIO}_{2}, \mathrm{PaO}_{2}, \mathrm{PaCO}_{2}, \mathrm{pH}$, $\mathrm{PaO}_{2}: \mathrm{FIO}_{2}$ ratio, arterial to alveolar $\mathrm{pO}_{2}$ ratio $\left(\mathrm{a}: \mathrm{APO}_{2}\right.$ ), PIP, mean airway pressure (MAP), inspiration:expiration ratio, PEEP, ventilatory efficiency index, ${ }^{4}$ and arterial blood pressure. The groups were also compared with respect to the following complications diagnosed within 28 days: pulmonary interstitial emphysema (PIE); pneumothorax; patent ductus arteriosus (PDA); intracerebral haemorrhage/(ICH); pulmonary haemorrhage; septicaemia; bronchopulmonary dysplasia (BPD); and death. Furthermore, total time of exposure to supplemental oxygen and complete duration of mechanical ventilation during hospital stay were recorded. Chest $x$ ray pictures were examined by a local paediatric radiologist who was not involved in the study and was blinded to the randomisation of the patients. PIE and pneumothorax were diagnosed according to recent definitions. ${ }^{13}$ Sequential echocardiograms and Doppler measurements to assess shunting across the ductus arteriosus were obtained every 24 hours during the first week 
Table 2 Patient details

\begin{tabular}{lcc}
\hline & Curosurf $\left(n=33^{\star}\right)$ & Survanta $(n=40)$ \\
\hline Gestational age, weeks (mean (SD)) & $28 \cdot 9(2 \cdot 3)$ & $28 \cdot 8(2 \cdot 2)$ \\
Birth weight $\mathrm{g}$ (mean (SD)) & $1095 \cdot 3(226 \cdot 4)$ & $1082 \cdot 4(252 \cdot 2)$ \\
Male sex (\%) & $11(33 \cdot 3)$ & $22(55 \cdot 0)$ \\
Prenatal steroids (\%) & $14(42 \cdot 4)$ & $15(37 \cdot 5)$ \\
Umbilical cord pH (mean (SD)) & $7 \cdot 31(0 \cdot 06)$ & $7 \cdot 27(0 \cdot 14)$ \\
Rectal temperature on admission $\left({ }^{\circ} \mathrm{C}\right) \dagger$ & $36 \cdot 5(36-37)$ & $36 \cdot 3(35 \cdot 6-37)$ \\
Age at treatment, hourst & $3 \cdot 2(2 \cdot 7-6 \cdot 1)$ & $3 \cdot 0(2 \cdot 6-4 \cdot 1)$ \\
FIO $_{2} \ddagger$ at randomisation $\dagger$ & $0 \cdot 9(0 \cdot 55-1 \cdot 0)$ & $0 \cdot 9(0 \cdot 7-1 \cdot 0)$
\end{tabular}

$\star$ No of patients included in the final calculations after exclusion of two patients (violation of entry criteria). $\nmid$ Median ( 25 th -75 th percentile). $\ddagger$ Fraction of inspired oxygen.

of life and whenever clinical signs of PDA were present. Ultrasonographic examinations of the head were performed daily for the first seven days and on day 10, and ICH was classified according to Papile et al $^{14}$; in surviving infants a further cranial ultrasound scan was performed at 28 days to look for ischaemic lesions. ${ }^{15}$ Pulmonary haemorrhage was defined as the appearance of bright red blood in the endotracheal tube associated with signs of clinical deterioration of the baby. Septicaemia was defined as clinical signs of systemic infection and positive blood culture. ${ }^{16}$ BPD was defined as oxygen requirement at a postconceptional age of 36 completed weeks.

The trial was approved by the ethics committee of the University of Göttingen and was performed in compliance with good clinical practice guidelines. This compliance took into account approval by relevant regulatory bodies, written informed consent of a parent before randomisation, and the 'CPMP Working Party on Efficacy of Medicinal Products: Notes for Guidance' on 'Good Clinical Practice for Trials on Medicinal Products in the European Community'.
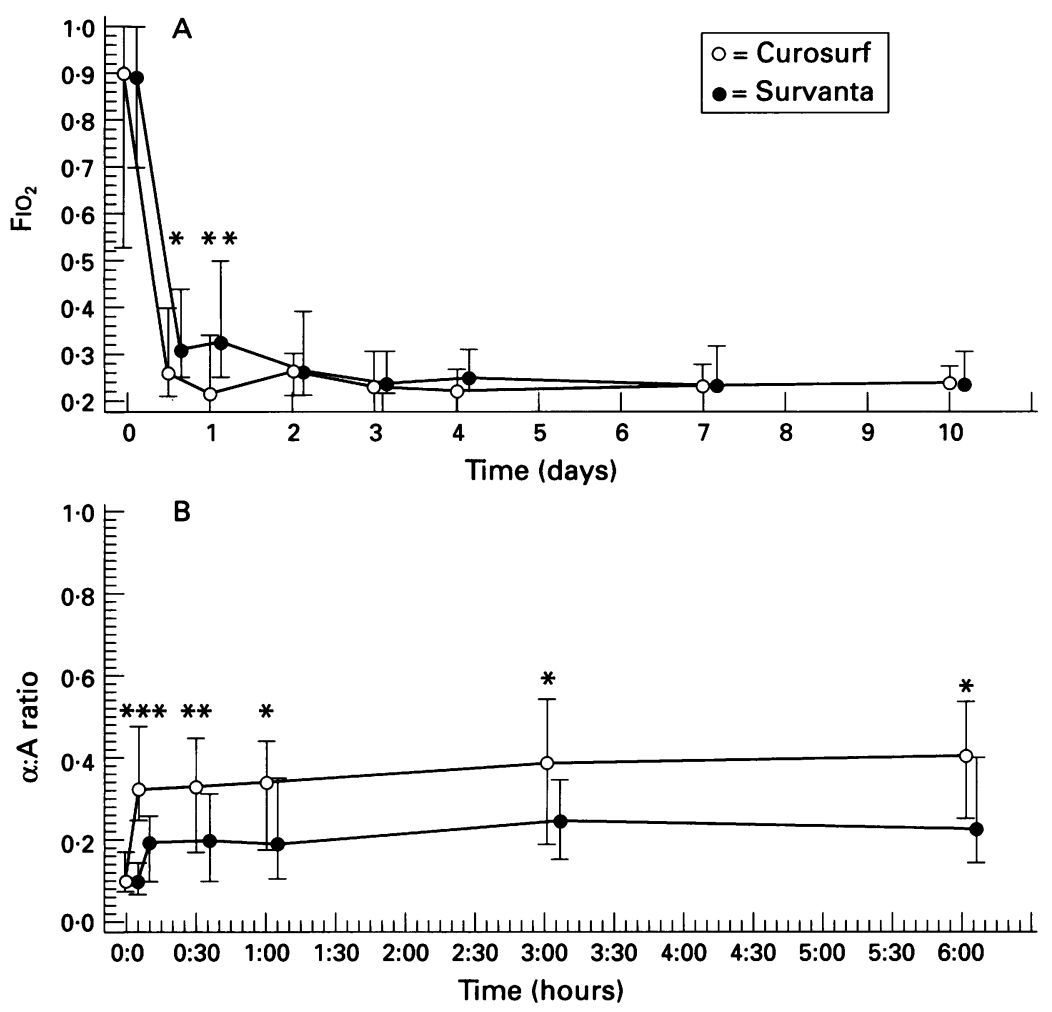

Figure 1 Oxygenation measurements in preterm infants with RDS treated with multiple doses of Curosurf or Survanta at various time points after randomisation. Values are given as median and 25th and 75th percentiles. The points for the two groups are offset for clarity. ${ }^{\star} p<0 \cdot 5,{ }^{\star} p<0 \cdot 01, \star \star \star p<0 \cdot 001$ : conversion factor: $10 \mathrm{~cm} \mathrm{H}_{2} \mathrm{O}=0.98 \mathrm{kPa}$.
STATISTICAL ANALYSIS

The statistical treatment of the trial data was approached by an intention-to-treat analysis of all eligible study subjects. ${ }^{17}$ Differences between the two randomised groups with respect to gas exchange and ventilatory settings at different time points were evaluated using the Wilcoxon-Mann-Whitney test. When the overall measures of ventilatory requirement and oxygen dependence were compared, the logrank test, with the data from all patients (not only the survivors), was used. ${ }^{18}$ As specified in the study protocol, logistic regression analysis was used to assess the effect of the surfactant treatment regimen on the 28 day outcome variables while simultaneously controlling for the confounding influence of birth weight, sex, and allocation to different hospitals. The resulting adjusted odds ratios (OR) represent approximate relative risks and are accompanied by their $95 \%$ confidence intervals. ${ }^{19}$

\section{Results}

CHARACTERISATION OF PATIENTS AND

TREATMENT REGIMENS

Thirty five patients were randomised to the Curosurf group and 40 to the Survanta group. For two babies who were randomised to Curosurf, treatment entry criteria had been violated (birth weight was $<700 \mathrm{~g}$ in one preterm infant and $>1500 \mathrm{~g}$ in the other). These infants therefore had to be excluded from further analyses (neither of them had pulmonary or extrapulmonary complications until discharge from the hospital, outcome results including these babies would have favoured the Curosurf group). Table 2 shows that the baseline characteristics of both groups were quite well matched, with the exception that the Curosurf group had a higher percentage of female babies. Median age at first treatment was about 3 hours in both groups, and in all patients the treatment was initiated before the age of 15 hours.

In the Curosurf group $16(49 \%)$ infants received a single dose, $11(33 \%)$ received two doses, and six $(18 \%)$ received three doses. The corresponding numbers in the Survanta group were $15(38 \%)$, nine $(23 \%)$, and eight $(20 \%)$. Eight $(20 \%)$ babies also received four doses of Survanta. Overall, $51.5 \%$ of the Curosurf and $62.5 \%$ of the Survanta babies needed multiple doses. The cumulative dose was 273 (SD 87) $\mathrm{mg} / \mathrm{kg}$ in the Curosurf group and 218 (115) $\mathrm{mg} / \mathrm{kg}$ in the Survanta group, and the number of patients requiring more than two doses was substantially larger in the Survanta group $(40.0 \% v 18.2 \% ; p=0.07$ derived from Fisher's exact test). Due to dosing errors, one Curosurf infant received a lower initial dose; in another baby the second Curosurf dose was doubled. In two Survanta babies the initial dose was too low, and in one a repeat dose of Survanta was given after 48 hours of age. One infant received the last Survanta dose at an $\mathrm{FiO}_{2}$ of $<0 \cdot 3$.

GAS EXCHANGE AND VENTILATOR SETTINGS AFTER SURFACTANT REPLACEMENT Initial treatment with Curosurf $(200 \mathrm{mg} / \mathrm{kg}$ ) or 

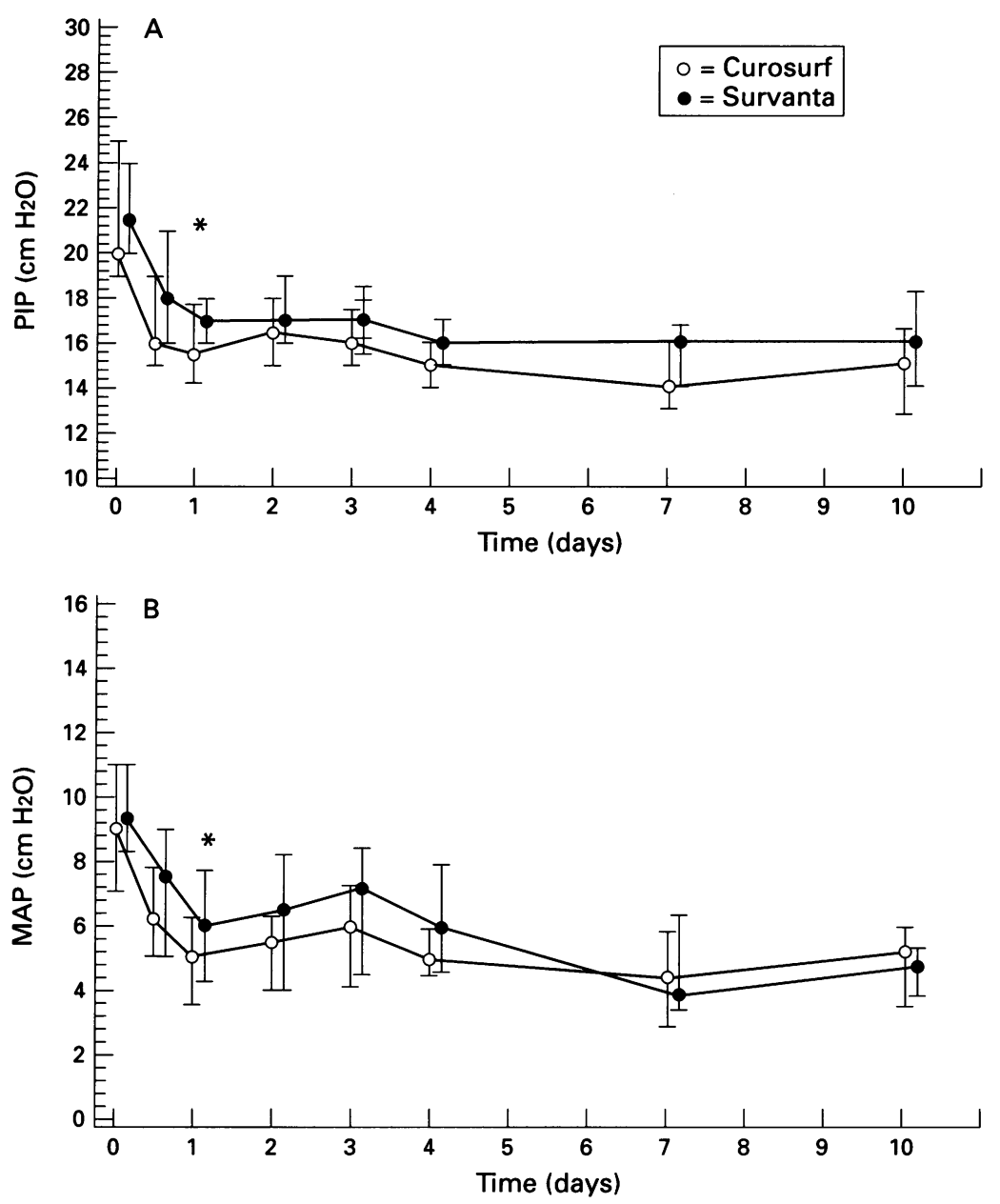

Figure 2 Peak inspiratory pressure $(P I P)(A)$ and mean airway pressure $(M A P)(B)$ in patients treated with multiple doses of Curosurf or Survanta at various time points after randomisation. Values are given as median and 25 th and 75 th percentile. The points for the two groups are offset for clarity. ${ }^{\star} p<0 \cdot 5,{ }^{\star \star} p<0 \cdot 01,{ }^{\star \star \star} p<0 \cdot 001$ : conversion factor: $10 \mathrm{~cm} \mathrm{H}_{2} \mathrm{O}=0.98 \mathrm{kPa}$.

Survanta $(100 \mathrm{mg} / \mathrm{kg}$ ) resulted in improved oxygenation. Median $\mathrm{FIO}_{2}$ could be lowered within five minutes, from 0.9 to 0.34 , in Curosurf neonates and from 0.9 to 0.5 in babies receiving Survanta (fig 1). However, between five minutes and six hours the Curosurf treatment patients needed less oxygen than the Survanta group $(\mathrm{p}<0.05-0.01)$; this difference was sustained until 24 hours $(p<0.05-0.001)$. During the first 24 hours after initial treatment the Curosurf babies also had a greater improvement in a: $\mathrm{APO}_{2}(\mathrm{p}<0.05-0.001)$ (fig 1).

PIP and MAP could gradually be reduced in both groups; however, at various time points the Curosurf treatment patients needed a lower PIP and MAP than the Survanta treated neonates $(p<0.05)$ (fig 2). The differences in oxygenation and ventilatory support favouring Curosurf treated infants did not persist beyond 24 hours after start of treatment. At

Table 3 Ventilatory requirement and oxygen dependency of surviving patients

\begin{tabular}{llll}
\hline & $\begin{array}{l}\text { Curosurf } \\
(n=32)\end{array}$ & $\begin{array}{l}\text { Survanta } \\
(n=35)\end{array}$ & $p$ Value \\
\hline $\begin{array}{l}\text { Duration of artificial ventilation in survivors, days } \dagger \\
\text { Total time of exposure to oxygen in survivors, days } \dagger\end{array}$ & $\begin{array}{l}14(6-20 \cdot 5 \\
16 \cdot 5(3 \cdot 5-38 \cdot 5)\end{array}$ & $\begin{array}{l}14(5-27) \\
10(3-28)\end{array}$ & $\begin{array}{l}0.494 \ddagger \\
0.274 \ddagger\end{array}$
\end{tabular}

†Median (25th-75th percentile).

$\ddagger$ Derived from the log-rank test (including the censored information of dead patients) representative time points the ventilatory efficiency index was not different between the groups: median values for the Curosurf and Survanta treatment babies before treatment were $0.12 v 0.13$, at 3 hours $0.16 v 0.14$, and at 6 hours $0.18 v 0.19\left(\mathrm{ml} / \mathrm{mm} \mathrm{Hg} / \mathrm{kg}^{-1}\right)$, respectively. Values for inspiration:expiration ratio, PEEP, arterial blood pressure, $\mathrm{PaO}_{2}, \mathrm{PaCO}_{2}$, and $\mathrm{pH}$ showed no relevant differences between the groups (data not shown).

\section{OUTCOME}

Table 3 shows the values for duration of artificial ventilation and total time of exposure to supplemental oxygen in surviving patients: there were no differences between the groups. An identical number of patients in each group also had a supplemental oxygen requirement at 36 weeks' postconceptional age.

One Curosurf baby died at the age of 18 days from massive hepatic bleeding following surgical repair for spontaneous intestinal perforation. In the Survanta group two infants died from grade IV ICH, two from acute cardiocirculatory failure (one had tension pneumothorax), and one due to respiratory failure probably related to lung hypoplasia after premature rupture of the membranes 17 days before delivery. Age at death ranged between 1 and 2 days.

Data on the treatment comparison for pulmonary and extrapulmonary complications are listed in table 4 . The incidences of most of the complications were lower in the Curosurf group, but with the small number of patients these trends towards favourable outcome following Curosurf treatment did not reach significance. The adjusted ORs given in table 4 represent the results of risk calculations for the effect of the treatment regimen (Curosurf $v$ Survanta) on the 28 day outcome variables controlled for the influence of birth weight, sex, and collaborating centre and thus do not reflect imbalances between treatment groups with respect to these prognostic factors.

Treatment administration problems were only observed in Survanta infants, probably reflecting the larger volume of the surfactant dose. Reflux of administered surfactant was observed in three, and oxygen saturation of less than $85 \%$ in two babies five minutes after administration.

\section{Discussion}

The results of our pilot trial show that infants treated with Curosurf had less oxygen and ventilator requirements than babies treated with Survanta. Although the long term measures of outcome favoured the Curosurf infants, the differences were not significant. These results, however, provide a sound basis for an accurate sample size calculation for the large scale trial to follow; a reduction from $25 \%$ to $15 \%$ for the occurrence of the primary endpoint 'death or BPD' is a reasonable assumption on the difference to be detected. Thus, a total of 708 infants is required in the definitive study to find 
Table 4 Comparison of 28 day outcome measurements with crude and adjusted odds ratios (OR) and 95\% confidence intervals (CI) as well as corresponding $p$ values in Curosurf $(n=33)$ and Survanta $(n=40)$ treated babies

\begin{tabular}{|c|c|c|c|c|c|c|}
\hline Outcome measurements & $\begin{array}{l}\text { Curosurf } \\
\text { No/\% }\end{array}$ & $\begin{array}{l}\text { Survanta } \\
\text { No/\% }\end{array}$ & $\begin{array}{l}\text { OR } \\
\text { crude }\end{array}$ & $\begin{array}{l}\text { OR } \\
\text { adjusted }^{\star \star}\end{array}$ & $\begin{array}{l}95 \% \text { CI of } \\
\text { adjusted OR }\end{array}$ & $\stackrel{p}{\text { Valuet }}$ \\
\hline $\begin{array}{l}\text { Pulmonary interstitial emphysema } \\
\text { Pneumothorax }\end{array}$ & $\begin{array}{l}1(3 \cdot 0) \\
2(6 \cdot 1)\end{array}$ & $\begin{array}{l}4(10 \cdot 0) \\
5(12 \cdot 5)\end{array}$ & $\begin{array}{l}0.28 \\
0.45\end{array}$ & $\begin{array}{l}0.30 \\
0.49\end{array}$ & $\begin{array}{l}0 \cdot 03-3 \cdot 42 \\
0 \cdot 08-2 \cdot 88\end{array}$ & $\begin{array}{l}0.33 \\
0.43\end{array}$ \\
\hline \multicolumn{7}{|l|}{ Intracerebral haemorrhage } \\
\hline Total & $7(21 \cdot 2)$ & $14(35 \cdot 0)$ & 0.50 & 0.44 & $0 \cdot 14-1 \cdot 36$ & $0 \cdot 15$ \\
\hline Grades 3-4 & $1(3 \cdot 0)$ & $5(12 \cdot 5)$ & 0.22 & $0 \cdot 18$ & $0 \cdot 02-1 \cdot 78$ & $0 \cdot 14$ \\
\hline Persistent ductus arteriosus & $18(54 \cdot 6)$ & $12(30 \cdot 0)$ & $2 \cdot 80$ & $2 \cdot 83$ & $0 \cdot 98-8 \cdot 21$ & 0.06 \\
\hline Bronchopulmonary dysplasia & $4(12 \cdot 5)$ & $4(11 \cdot 4)$ & $1 \cdot 11$ & 1.03 & $0 \cdot 21-5 \cdot 21$ & 0.97 \\
\hline Pulmonary haemorrhage & $0(0)$ & $1(2 \cdot 5)$ & - & - & - & - \\
\hline \multicolumn{7}{|l|}{ Septicaemia: } \\
\hline Total No & $12(36 \cdot 4)$ & $11(27 \cdot 5)$ & 1.51 & 1.33 & $0 \cdot 37-4 \cdot 81$ & 0.66 \\
\hline Onset $\leqslant 2$ days & $6(18 \cdot 2)$ & $4(10.0)$ & 1.94 & 1.55 & $0 \cdot 32-7 \cdot 43$ & 0.58 \\
\hline Onset $>2$ days & $6(18 \cdot 2)$ & $7(17 \cdot 5)$ & 1.05 & 1.02 & $0 \cdot 24-4 \cdot 30$ & 0.98 \\
\hline Mortality & $1(3.0)$ & $5(12 \cdot 5)$ & $0 \cdot 22$ & 0.23 & $0 \cdot 02-2 \cdot 54$ & $0 \cdot 23$ \\
\hline
\end{tabular}

* Derived from the fourfold table of treatment times outcome.

$\star \star$ Derived from the logistic model incorporating covariate information.

$\dagger$ Derived from the test in the logistic model whether the adjusted OR equals 1

‡Oxygen dependency at 36 weeks' postconceptional age.

such a difference with $90 \%$ power using a twosided test at a significance level of $5 \%$.

In general, the data of the present pilot study must be interpreted with caution. The trend towards favourable 28 day outcome in Curosurf treated infants has to be viewed in the light of the small number of babies enrolled in the study and the non-blind trial design. Although we are not aware of any systematic bias in the assessment of outcome measures, we cannot rule out this possibility. However, additional data analysis stratified by collaborating centre did not indicate heterogeneity in our results. Thus, if systematic bias were present it would have to be the same in all centres, which seems unlikely.

There are at least three possible explanations for the improved lung function in the Curosurf treated babies during the first 24 hours. These are, firstly, that the trial collaborators had more experience with the porcine surfactant preparation; secondly, the Curosurf is a more effective surfactant than Survanta; and thirdly, that the dose of phospholipids namely, $200 \mathrm{mg} / \mathrm{kg} v 100 \mathrm{mg} / \mathrm{kg}$ was critical.

The first explanation seems very unlikely. Although the collaborating neonatologists have participated in previous Curosurf trials, ${ }^{46}$ their expertise in administering Survanta is comparable as each of the centres had been using Survanta in routine clinical practice for many months before the trial started.

The two surfactant preparations used in the present trial differ in some potentially important biophysical characteristics. Curosurf and Survanta are both derived from minced animal lungs by washing and extraction with organic solvents; this latter procedure removes water soluble components including the surfactant associated apoproteins SP-A and SP-D, leaving only hydrophobic constituents with about $1 \%$ SP-B and SP-C. Curosurf is further 'purified' by a liquid-gel chromatography procedure removing neutral lipids such as triacylglycerol, cholesterol, and cholesteryl esters. ${ }^{11}$ Survanta, in contrast, is enriched with synthetic DPPC, triacylglycerol, and palmitic acid to standardise lipid composition and reduce film compressibility. It is not clear how these different modifications of the surfactant preparations influence their physiological properties under in vivo conditions. Nohara et al confirmed that in vitro film compressibility of a bovine equivalent to Curosurf could indeed be lowered by enrichment with synthetic lipids ${ }^{20}$; however, this was associated with retarded spreading and did not seem to improve further physiological variables of lung mechanics in ventilated immature newborn rabbits.

The present trial was designed to investigate whether these differences in biochemical and biophysical properties between the two preparations would have an impact on their clinical effects in babies with RDS. We realise that, under optimal trial conditions, Curosurf and Survanta should have been given at identical doses and treatment intervals in a blind manner. However, this was not possible, as different treatment regimens were already established for each of the two surfactants. The trial design thus implied that Curosurf was given at a larger initial dose, whereas the maximum dose during the first two days of postnatal life was the same for the two preparations. We found that, after administration of either Curosurf or Survanta, there was a rapid improvement of gas exchange, as reflected by a significant increase in a: $\mathrm{APO}_{2}$, and $\mathrm{FIO}_{2}$ could therefore be reduced in both groups of babies. However, five minutes to 24 hours after surfactant replacement Curosurf treated infants needed less oxygen than patients in the Survanta group and had a more noticeable improvement in a:APO . Apparently, the effect of the Survanta treatment regimen was delayed.

At some time points PIP and MAP were significantly lower in the Curosurf group than in the Survanta group. Five minutes after instillation of Survanta a slight increase in median PIP was observed; this phenomenon could have been due to the larger volume of the initial Survanta dose compared with the Curosurf dose. The superior improvement in oxygenation and ventilatory pressure in the Curosurf group may reflect the higher initial dose $(200 \mathrm{mg} / \mathrm{kg}$ Curosurf $v 100 \mathrm{mg} / \mathrm{kg}$ Survanta) or the different preparation. The difference in ventilatory requirements between the groups might explain the trend towards the lower incidence of PIE and pneumothorax in Curosurf babies compared with Survanta babies. There was also a trend towards lower incidence of $\mathrm{ICH}$ in the 
Curosurf group; severe ICH was present in only one $(3 \%)$ of the Curosurf treated infants and in five $(12.5 \%)$ patients in the Survanta group. Our data support the concept that babies with RDS benefit from receiving a high initial dose 4 and also indicate that a high initial dose reduces the need for retreatment. Each administration procedure, which involves deconnection from the ventilator and instillation of fluid into the airways, is potentially traumatic and usually associated with a slight drop in arterial blood pressure, ${ }^{21}$ and may even lead to transient depression of cerebroelectrical activity. ${ }^{22}$

In summary, we feel confident in concluding that preterm infants with RDS treated according to the Curosurf regimen had improved oxygenation and reduced ventilatory requirements during the first 24 hours compared with Survanta treated neonates. There was also a trend towards lower incidence of air leaks and severe ICH in babies receiving Curosurf. These findings need to be confirmed in a larger randomised trial.

The trial was supported in part by a research grant from Chiesi Farmaceutici SpA, Parma, Italy, but was designed, conducted, and analysed independently of the company.

The trial is dedicated to our friend and trial collaborator $\mathrm{Dr}$ Edgar Laufkötter, who died in April 1994.

We are grateful for the support given by the attending intensive care nurses and neonatologists in all contributing units and acknowledge the assistance of Mrs Astrid Becker-Keymling in all organisational aspects of the trial.

1 Jobe AH. Pulmonary surfactant therapy. $N$ Engl $\mathcal{f}$ Med 1993; 328: 861-8.

2 Horbar JD, Wright LL, Soll RF, Wright EC, Fanaroff AA Korones SB, et al. A multicentre randomized trial comparing two surfactants for the treatment of neonatal respiratory distress syndrome. $\mathcal{F}$ Pediatr 1993; 123: 757-66.

3 Collaborative European Multicenter Study Group. Surfactant replacement therapy for severe neonatal respiratory distress syndrome: an international randomized clinical trial. Pediatrics 1988; 82: 683-91.

4 Speer CP, Robertson B, Curstedt T, Halliday HL, Compagnone D, Gefeller $\mathrm{O}$, et al. Randomized European multicenter trial of surfactant replacement therapy for multicenter trial of surfactant replacement therapy for severe neonatal respiratory distress syndrome: single ver-
sus multiple doses of Curosurf. Pediatrics 1992; 89: sus multir $13-20$.

5 Egberts J, de Winter JP, Sedin G, de Kleine NJK, Broberger $\mathrm{U}$, van Bel $\mathrm{O}$, et al. Comparison of prophylaxis and rescue treatment with Curosurf in babies less than 30 weeks gestation. A randomized trial. Pediatrics 1993; 92: 768-74.
6 Halliday HL, Tarnow-Mordi WO, Corcoran JD, Patterson CC. A multicentre randomised trial comparing high and low dose surfactant regimens for the treatment of respiralow dose surfactant regimens for the treatment of respiratory distress syndrome

7 Horbar JD, Soll RF, Sutherland JM, Kofagal U, Philip AGS, Kessler DL, et al. A multicenter randomized, placebo-controlled trial of surfactant therapy for respiratory distress syndrome. $N$ Engl $₹$ Med 1989; 320: 959-65.

8 Soll RF, Hoekstra RE, Fangman JJ, Corbet AJ, Adams JM James LS, et al. Multicenter trial of single-dose modified bovine surfactant extract (Survanta) for prevention of respiratory distress syndrome. Pediatrics 1990; 85: 1092-102.

9 Hoekstra RE, Jackson JC, Myres TF, Frantz JD, Stern ME, Powers WF, et al. Improved neonatal survival following multiple doses of bovine surfactant in very premature multiple doses of bovine surfactant in very premature neonates at risk for resp

10 Fujiwara T, Robertson B. Pharmacology of exogenous surfactant. In: Robertson B, van Golde LMG, Battenburg JJ, eds. Pulmonary surfactant: from molecular biology to clinical practice. Amsterdam: Elsevier Science, 1992: 561-92.

11 Robertson B, Curstedt T, Johansson J, Jörnvall $H$, Kobayashi T. Structural and functional characterization of porcine surfactant isolated by liquid-gel chromatography. In: von Wichert P, Müller B, eds. Basic research on lung surfactant. Progress in Respiration Research. Vol 25. Basel: Karger, 1990: 237-46.

12 Liechty EA, Donovan E, Purohit D, Gilhooly J, Feldmann $\mathbf{B}$, Noguchi $\mathbf{A}$, et al. Reduction of neonatal mortality after multiple doses of bovine surfactant in low birth weight multiple doses of bovine surfactant in low birth weight neonates with resp

13 Speer CP, Reuß D, Harms K, Herting E, Gefeller O. Neutrophil elastase and acute pulmonary damage in infants with severe respiratory distress syndrome. Pediatrics 1993; 91: 794-9.

14 Papile LA, Burstein J, Burstein R, Koffler H. Incidence and evolution of subependymal and intraventricular hemorrhage: a study of infants birth weight less than $1500 \mathrm{~g}$. f Pediatr 1978; 92: 529-34.

15 Fawer CL, Diebold P, Calame A. Periventricular leucomalacia and neurodevelopmental outcome in preterm infants. Arch Dis Child 1987; 62: 30-6.

16 Speer CP, Rethwilm M, Gahr M. Elastase- $\alpha_{1}$-proteinase inhibitor: an early indicator of septicemia and bacterial meningitis in children. $\mathcal{F}$ Pediatr 1987; 111: 667-71.

17 Newell DJ. Intention-to-treat analysis: implications for quantitative and qualitative research. Int f Epidemiol 1992; 21: $837-41$

18 Kalbfleisch JD, Prentice RL. The statistical analysis of failure time data. New York: John Wiley and Sons, 1980

19 Hosmer DW, Lemeshow S. Applied logistic regression. New York: John Wiley and Sons, 1989.

20 Nohara K, Berggren P, Curstedt T, Grossman G, Nilsson R, Robertson B. Correlations between physical and physiological properties of various preparations of lung surfactant. Eur f Respir Dis 1986; 69: 321-35.

21 Skov K. Hellström-Westas L, Jacobsen T, Greisen G, Svenningsen NW. Acute changes in cerebral oxygenation and cerebral blood volume in preterm infants during surfactant treatment. Neuropediatrics 1992; 23: during $126-30$.

22 Hellström-Westas L, Bell AH, Skov L, Greisen G, Svenningsen NW. Cerebroelectrical depression following surfactant treatment in preterm neonates. Pediatrics 1992; 89: 643-7. 